\title{
Using Pd-Doped $\gamma$-Graphyne to Detect Dissolved Gases in Transformer Oil: A Density Functional Theory Investigation
}

\author{
Xiaoxing Zhang ${ }^{1,2,3}$, Rongxing Fang ${ }^{1}$, Dachang Chen ${ }^{2, *}$ and Guozhi Zhang ${ }^{1}$ \\ 1 Hubei Key Laboratory for High-efficiency Utilization of Solar Energy and Operation Control of Energy \\ Storage System, Hubei University of Technology, Wuhan 430068, China; xiaoxingzhang@whu.edu.cn (X.Z.); \\ 101900155@hbut.edu.cn (R.F.); 20191062@hbut.edu.cn (G.Z.) \\ 2 School of Electrical Engineering and Automation, Wuhan University, Wuhan 400044, China \\ 3 State Key Laboratory of Power Transmission Equipment \& System Security and New Technology, \\ Chongqing University, Chongqing 400044, China \\ * Correspondence: dachangchen@whu.edu.cn
}

Received: 24 September 2019; Accepted: 12 October 2019; Published: 19 October 2019

\begin{abstract}
To realize a high response and high selectivity gas sensor for the detection dissolved gases in transformer oil, in this study, the adsorption of four kinds of gases $\left(\mathrm{H}_{2}, \mathrm{CO}, \mathrm{C}_{2} \mathrm{H}_{2}\right.$, and $\left.\mathrm{CH}_{4}\right)$ on Pd-graphyne was investigated, and the gas sensing properties were evaluated. The energeticallyfavorable structure of Pd-Doped $\gamma$-graphyne was first studied, including through a comparison of different adsorption sites and a discussion of the electronic properties. Then, the adsorption of these four molecules on Pd-graphyne was explored. The adsorption structure, adsorption energy, electron transfer, electron density distribution, band structure, and density of states were calculated and analyzed. The results show that Pd prefers to be adsorbed on the middle of three $\mathrm{C} \equiv \mathrm{C}$ bonds, and that the band gap of $\gamma$-graphyne becomes smaller after adsorption. The $\mathrm{CO}$ adsorption exhibits the largest adsorption energy and electron transfer, and effects an obvious change to the structure and electronic properties to Pd-graphyne. Because of the conductance decrease after adsorption of $\mathrm{CO}$ and the acceptable recovery time at high temperatures, Pd-graphyne is a promising gas sensing material with which to detect $\mathrm{CO}$ with high selectivity. This work offers theoretical support for the design of a nanomaterial-based gas sensor using a novel structure for industrial applications.
\end{abstract}

Keywords: Pd-Doped graphyne; dissolved gases; adsorption; density functional theory (DFT)

\section{Introduction}

At present, 2D materials are attracting much attention after the successful synthesis of graphene by micromechanical exfoliation in 2004 [1]. Because of the excellent physical and chemical properties of graphene, including high surface area and activity, high thermal conductivity, good heat dissipation, sensitive light response, and gas/ion response, graphene has found broad application value and development space [2-4]. Nonetheless, the difficulty of operating the zero value of the band gap restricts its wide use in industrial processes. Based on this, several emerging 2D materials have been exploited, including transition metal dichalcogenides (TMDs) [5,6], isomers of graphene [7], metal carbides and nitrides [8], 2D metal-organic frameworks [9], etc. Because of their more flexible band structures, these materials could have more promising applications in the field of optical and electronic devices.

Among numerous 2D carbon allotropies, graphyne (GY) remains one of the most popular monolayer materials [10-12]. The two most popular structures, $\gamma$-graphyne $(\gamma-\mathrm{GY})$ and graphdiyne (GDY), both have $\mathrm{sp}^{2}$ - and sp-hybridized carbon atoms. The difference is that in $\gamma-\mathrm{GY}$, only one C-C 
triple bond is present between two hexagonal carbon rings, while two triple bonds occur between the two rings in GDY [10-12]. Previous studies using theoretical methods have shown that several structures of graphyne are physically and chemically stable, such as $\alpha$-graphyne ( $\alpha$-GY), $\beta$-graphyne $(\beta-G Y), 6,6,12$-graphye [11], etc. In contrast to graphene and graphite, $C \equiv C$ triple bonds appear in all types of graphyne. The ratio of bond type of the acetylenic linkages of $\alpha-G Y, \beta-G Y$, and $\gamma-G Y$ is different. $\alpha$-GY has $100 \%$ acetylenic linkages, while $\beta$-GY and $\gamma$-GY have $66.67 \%$ and $33.33 \%$, respectively [13]. Different types of GY also have different band structures. For $\alpha-G Y$ and $\beta-G Y$, the valence band and conduction band cross to one point, while $\gamma$-GY has a direct band gap of about $0.471 \mathrm{eV}$, as measured using the generalized gradient approximation (GGA) approach [14]. But graphdiyne (GDY) was the first one reported to be synthesized in experiment [15]. However, although $\gamma$-GY has not been prepared practically, several theoretical studies have shown that it has promising uses in field of catalysis, energy storage, gas/ion sensor, and electronic/optical devices. $\gamma-$ GY may be a promising catalyst for oxygen reduction reactions (ORRs), nitrogen reduction reactions (NRRs) etc. After the doping of metal or non-metal atoms, graphyne has excellent catalytic performance, and it may be used as a single-atom catalytic material in the future [16,17]. As for the adjustment of the physical properties of $\gamma-G Y$, e.g., the electronic and magnetic properties, the introduction of impurities and surface defects is an effective method [18-21]. The doping of metal atom clusters is also a feasible method to adjust the surface activity and electronic properties [22-24]. GY is also a promising gas sensing material in many fields. Pristine GY has been shown to interact weakly with most common gas molecules, e.g., $\mathrm{CO}, \mathrm{CH}_{4}$, $\mathrm{CO}_{2}, \mathrm{NH}_{3}$, and $\mathrm{NO}$, among others [25,26]. Doping with Mn can obviously strengthen the chemical interactions between these molecules and the $\gamma$-GY surface [26]. For the gas detection of CO molecules, to improve the weak response, the substitution doping with B and N makes GY more sensitive to $\mathrm{CO}$ [27]. For the detection of $\mathrm{NH}_{3}$, doping the main group atom, e.g., $\mathrm{Si}$, can significantly reduce the recovery time [28]. The substitution doping of $\mathrm{B}$ can also enhance the gas sensing properties for several inorganic, small molecules such as $\mathrm{NO}$ and $\mathrm{NO}_{2}$, as well as organic molecules [29,30]. The doping of noble atoms has also been shown to significantly enhance the chemical interactions between $\mathrm{CO}$ and $\gamma$-GY [31]. Based on several theoretical studies of GY as a gas sensing material, pristine GY exhibits weak chemical interactions with most small gas molecules. To enhance the gas sensing properties, introducing an adatom onto the surface is advisable. And also, choosing the appropriate doping approach is essential for the selectivity of GY-based sensing materials.

High voltage equipment has been widely used in power stations, transformer substations, and power distribution stations. To guarantee the operational status of equipment such as transformers using oil-paper insulation or gas-insulated switchgears (GISs) using $\mathrm{SF}_{6}$ as an insulating medium, detecting impurity gases using gas sensors has been widely studied. For the detection of $\mathrm{SF}_{6}$ decomposition, several 2D materials have been explored, and surface modification including doping transition metal atoms or metal oxides are feasible to enhance the chemical interactions between the $\mathrm{SF}_{6}$ decompositions and the sensing materials [32-41]. Several impurity gases, such as $\mathrm{CO}, \mathrm{H}_{2}, \mathrm{C}_{2} \mathrm{H}_{2}$, $\mathrm{CH}_{4}, \mathrm{C}_{2} \mathrm{H}_{6}$, and $\mathrm{C}_{2} \mathrm{H}_{4}$, will be generated and dissolve in the oil in the transformer after insulation faults occur. So, a dissolved gas analysis (DGA) method is essential for equipment inspection. In view of this, several materials have been studied to detect these kinds of molecules, including metal oxides [42-47] and TMDs [46-48]. However, the selectivity and the enhancement of the sensitivity should be further considered. In this regard, due to the high surface activity of $\gamma$-GY, and the emerge active sites caused by the introduction of $\mathrm{Pd}[42,44,45]$, in this study, we propose a DFT study of four typical dissolved gases in transformer oil $\left(\mathrm{H}_{2}, \mathrm{CO}, \mathrm{C}_{2} \mathrm{H}_{2}\right.$, and $\left.\mathrm{CH}_{4}\right)$ which are adsorbed onto Pd-doped $\gamma$-GY. Firstly, the adsorption of one $\mathrm{Pd}$ atom on $\gamma-\mathrm{GY}$ was discussed, and the most energetically-favorable structure of Pd-GY was found. Then, the adsorption of gas molecules onto the Pd-GY was investigated and the adsorption energy, electron transfer, and electronic properties were studied in detail. Finally, the different responses to these gases were evaluated. We believe that this study may provide a theoretical basis for graphyne-based nanomaterials to detect dissolved gases in oil, and guidance for the future development of nanomaterial-based gas sensors in many fields. 


\section{Methods}

All the adsorption of Pd and gas molecules on $\gamma$-GY are calculated in the Dmol ${ }^{3}$ module [49]. The Perdew-Burke-Ernzerhof function (PBE) approach by generalized gradient approximation (GGA) was chosen for correction of the exchange-correlation function [50,51]. The total energy, band structure, and density of states (DOS) were also calculated using the GGA-PBE approximation method. The double numerical plus polarization (DNP) method was considered as the basis set for all the calculations, and the DFT semi-core pseudopotential (DSSP) was selected to handle the electrons, that is, a norm-conserving pseudopotential was applied to calculate the core electrons to improve the calculation efficiency. The long-range interactions derived from the Van der Walls force was calculated using the DFT-D2 method, as proposed by Grimme [52]. A cutoff radius of $4.5 \AA$ was set, and this value remained unchanged in this study. All geometric optimizations between the two steps were carried out using a convergence criterion of $1 \times 10^{-5} \mathrm{Ha}$ for energy convergence, $0.002 \mathrm{Ha} / \AA$ f for force convergence, and $0.005 \AA$ for displacement convergence. A k-point sample in the Monkhorst-Pack grid of $4 \times 4 \times 1$ was used for geometric optimization, while a more accurate k-point was considered in the electronic properties with a Gaussian smearing of $0.005 \mathrm{Ha}$ [53]. The binding energy $\left(E_{a d s}\right)$ was calculated using the following equation:

$$
E_{\text {bind }}=E_{P d-\text { graphyne }}-E_{\text {graphyne }}-E_{P d \text { atom }}
$$

where $E_{P d-g r a p h y n e} E_{\text {graphyne, }}$ and $E_{P d \text { atom }}$ are the total energy of Pd-graphene, pristine graphyne monolayer, and isolated $\mathrm{Pd}$ atom. After the adsorption of one $\mathrm{Pd}$ atom, the electron transfer was obtained using the Hirshfeld analysis method [54]:

$$
Q=-\int\left(\frac{\rho_{0}(r)}{\sum \rho_{0}{ }^{\prime}(r)}\right) \cdot\left(\rho(r)-\sum \rho_{0}^{\prime}(r)\right) d r
$$

where $\rho(r)$ is the total electron density of the selected structure, and $\rho_{0}(r)$ represents the electron density of every atom if separated. $\sum \rho_{0^{\prime}}(r)$ is the sum of $\rho_{0}(r)$.

The adsorption sites of $\mathrm{Pd}$ are shown in Figure 1; considering all the structures of the different adsorption sites, the structure with the largest binding energy was chosen for gas adsorption. The adsorption energy of one gas molecule on Pd-graphyne is defined as:

$$
E_{a d s}=E_{P d-\text { graphyne/gas }}-E_{P d-\text { graphyne }}-E_{g a s}
$$

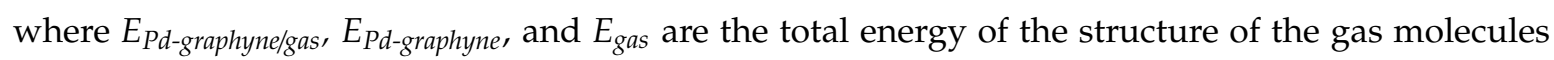
adsorbed onto Pd-graphene, Pd-graphyne before the adsorption, and isolation of the gas molecule. All the electron transfers between the gas molecule and Pd-graphyne were also clarified based on the Hirshfeld analysis method. When the electron transfer of $Q_{T}$ is negative, it indicates that the gas molecule extracts electrons from the Pd-graphyne, while if $\mathrm{Q}_{\mathrm{T}}$ is positive, it indicates that the gas molecule transfers electrons to Pd-graphyne. To gain a deeper understanding of the electron transfer, the electron density difference between the molecule and the Pd-graphyne can be obtained after calculating the electron density as follows:

$$
\Delta \rho=\rho_{P d-\text { graphyne } / \text { gas }}-\left(\rho_{P d-\text { graphyne }}+\rho_{\text {gas }}\right)
$$

where $\rho_{P d-g r a p h y n e / g a s}, \rho_{P d-g r a p h y n e}$ and $\rho_{\text {gas }}$ are the total electron density of Pd-graphyne after adsorbing the molecule, that of Pd-graphyne before adsorption, and that of the isolated molecule, respectively. The purple and red regions are the electron accumulation regions, while the green and blue regions represent electron depletion.

The band structure, the total density of states (TDOS), and the partial density of states (PDOS) were also compared before and after gas adsorption 


\section{Results and Discussion}

\subsection{The Structure of Pd-Graphyne and Dissolved Gas in Transformer Oil}

The calculated lattice parameter of $\gamma$-GY in this study is $6.89 \AA \times 6.89 \AA$, which is consistent with the former results [13,29]. We built a $2 \times 2$ super cell and put one $\mathrm{Pd}$ atom on the surface with different adsorption sites. The stoichiometric proportion of $\mathrm{Pd}$ and $\mathrm{C}$ is $1: 48$. The adsorption sites of $\mathrm{Pd}$ on the $\gamma$-GY surface are shown in Figure 1, including two hollow sites (H1, H2) and three bridge sites (B1, B2, and B3). The initial five structures of Pd-graphyne are fully geometrically optimized. The optimized structures are shown in Figure 2, and the summary of the binding energy and electron transfers are listed in Table 1. According to a comparison of the binding energy, adsorption on the H1 site exhibits the largest energy, indicating that one Pd atom on $\gamma$-GY has the most energetically-favorable structure. In Figure 2a, the Pd atom is located in the middle of three $\mathrm{C} \equiv \mathrm{C}$ bonds. The distance between Pd and one hybridized $\mathrm{C}$ atom is about $2.10 \AA$. It is important to note that the Pd atom is not totally in the plane of the $\gamma$-GY, but rather, it extrudes from the surface by about $0.057 \AA$. The binding energy of the $\mathrm{Pd}$ on the $\mathrm{H} 1$ site is $-2.45 \mathrm{eV}$, with an electron transfer from Pd to $\gamma-\mathrm{GY}$ of +0.363 e. The adsorbed $\mathrm{Pd}$ atom is positively charged. The adsorption on the B3 site exhibits the second largest adsorption energy, while other adsorption energies are smaller. Based on a comparison of the binding energy, we will focus solely on the structure with the largest binding energy for further discussion, i.e., electronic properties and gas adsorption.

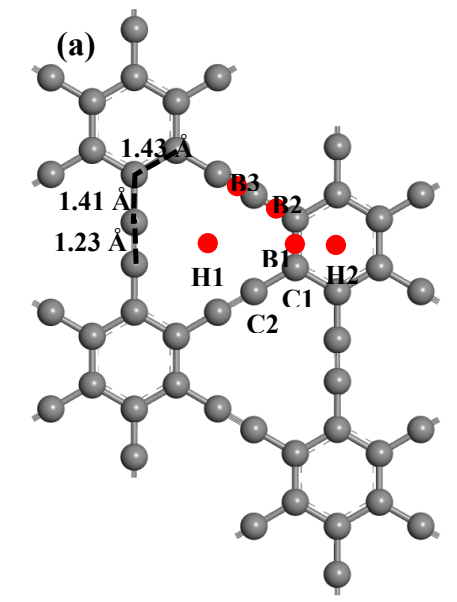

(b)

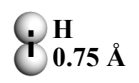

(d)

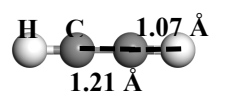

(c)

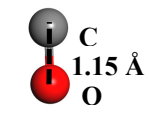

(e)

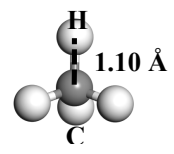

Figure 1. Geometric structures of: (a) pristine graphyne with different adsorption sites; (b) $\mathrm{H}_{2}$; (c) CO; (d) $\mathrm{C}_{2} \mathrm{H}_{2} ;(\mathbf{e}) \mathrm{CH}_{4}$.

Table 1. Binding energy and electron transfer of one Pd atom onto a graphyne monolayer.

\begin{tabular}{ccc}
\hline Adsorption Site & $\boldsymbol{E}_{\text {bind }}(\mathbf{e V})$ & $\boldsymbol{Q}_{T}(\mathbf{e})$ \\
\hline H1 site & -2.45 & +0.363 \\
H2 site & -1.08 & +0.323 \\
B1 site & -1.59 & +0.344 \\
B2 site & -1.52 & +0.315 \\
B3 site & -1.76 & +0.273 \\
\hline
\end{tabular}

The band structures and DOS of pristine $\gamma$-GY and Pd-graphyne obtained by the PBE method are shown in Figure 3. Pristine $\gamma$-GY has a direct band structure with a $0.42 \mathrm{eV}$ band gap at the Gamma point. This value is very similar to that obtained in other studies $(0.43 \mathrm{eV}$ in ref. [23] and $0.435 \mathrm{eV}$ in ref. [55]). The TDOS also shows a gap near $0 \mathrm{eV}$. It should be noted that the Fermi-level $(0 \mathrm{eV})$ in $\mathrm{Dmol}^{3}$ module is set at the highest occupied state, and thus, the imaginary line is in the middle of the highest occupied peak in Figure 3a. So, the non-zero value at $0 \mathrm{eV}$ is mainly because of the broadening of the peak. After doping the Pd atom, the band structure also shows a direct band gap and the value 
decreases to $0.33 \mathrm{eV}$. The Pd atom mainly introduces several impurity states near $-2.5 \mathrm{eV}$ to $0 \mathrm{eV}$. The Pd atom also slightly changes its band distribution near $0 \mathrm{eV}$, and thus, decreases the band gap. We will only consider the adsorption of gas molecules on the structure in Figure 2a in the next section.
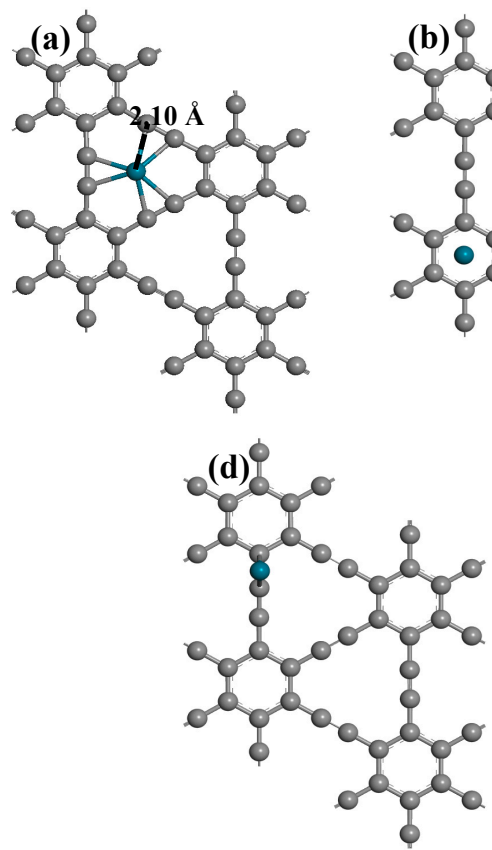
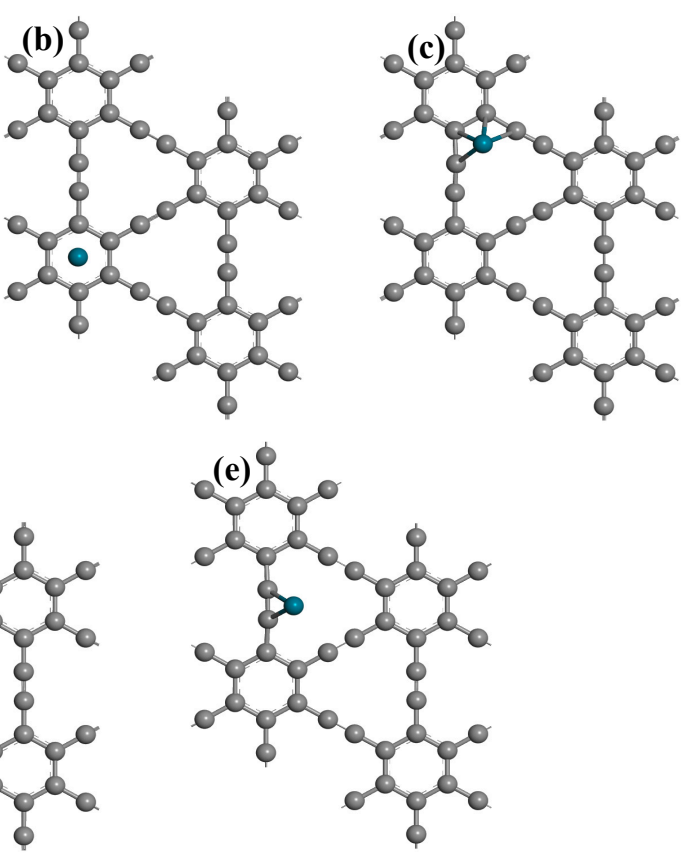

Figure 2. Optimized geometric structures of one Pd atom adsorbed on graphyne: (a) H1 site; (b) H2 site; (c) B1 site; (d) B2 site; (e) B3 site.
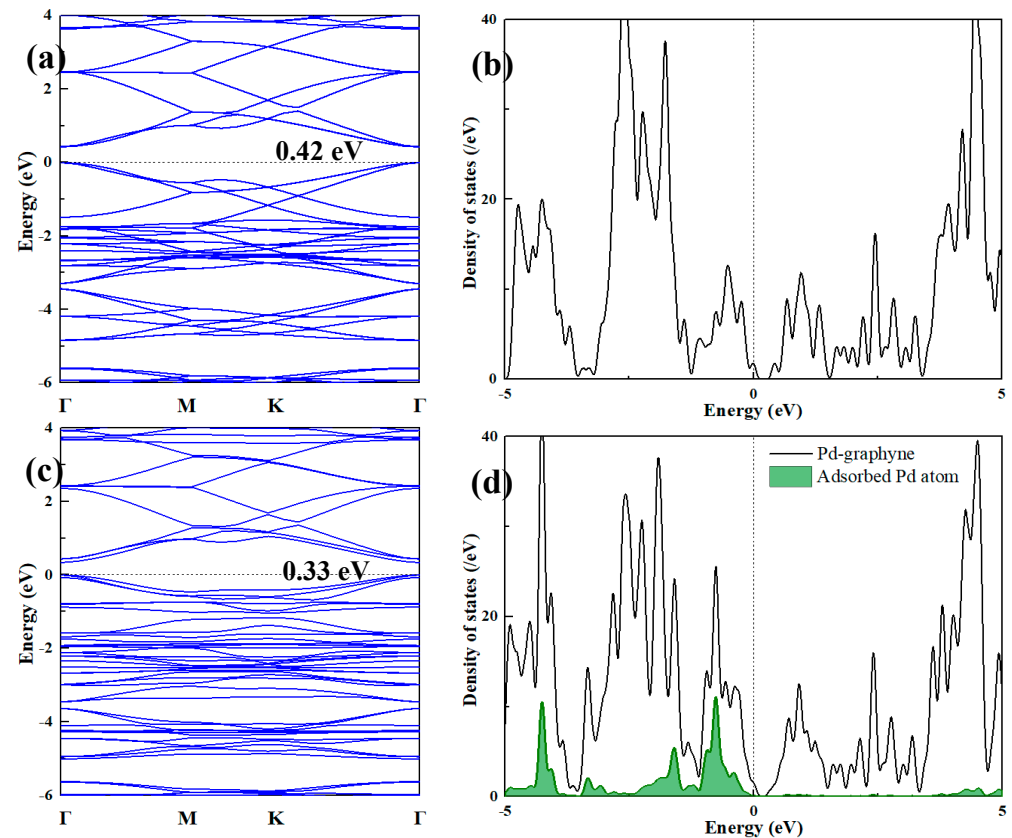

Figure 3. (a) Band structure and (b) TDOS of pristine graphyne; (c) Band structure and (d) TDOS of Pd-graphyne and PDOS of adsorbed Pd atom.

The structure of four kinds of gas molecules are shown in Figure $1 \mathrm{~b}-\mathrm{e} . \mathrm{H}_{2}$ and $\mathrm{CO}$ are diatomic molecules, while the $\mathrm{C}$ atoms in $\mathrm{C}_{2} \mathrm{H}_{2}$ are sp hybridized and the $\mathrm{C}$ atom in $\mathrm{CH}_{4}$ is sp ${ }^{3}$ hybridized. The structures conform to the results obtained in our previous study [46-48]. For the initial adsorption structure, we considered two adsorption directions for $\mathrm{H}_{2}$ onto the $\mathrm{Pd}$ atom $\left(\mathrm{H}_{2}\right.$ parallel to the surface and vertical to the surface), two adsorption directions of $\mathrm{CO}$ over the Pd atom ( $\mathrm{C}$ atom downward and 
$\mathrm{O}$ atom downward), one adsorption direction of $\mathrm{C}_{2} \mathrm{H}_{2}$ (the $\mathrm{C} \equiv \mathrm{C}$ bond right above the $\mathrm{Pd}$ atom), and two adsorption directions of $\mathrm{CH}_{4}$ (one $\mathrm{H}$ atom downward and three $\mathrm{H}$ atoms downward). Only the structures with the largest adsorption energy of each gas molecule were chosen for further study.

\subsection{Adsorption of Gas Molecule on Pd-Graphyne}

The most energetically-favorable adsorption structures of gas molecules on Pd-graphyne are shown in Figure 4; the adsorption energy and electron transfers are listed in Table 2. The $\mathrm{H}_{2}$ molecule prefers to be adsorbed vertically to the surface right above the Pd atom. The adsorption brings only $-0.08 \mathrm{eV}$ adsorption energy and -0.059 e electron transfer. The adsorption distance is $2.58 \AA$. The Pd atom remains its former position. The adsorption of $\mathrm{CO}$ occurs somewhat differentely. The $\mathrm{C}$ atom in $\mathrm{CO}$ prefers to be right above the $\mathrm{Pd}$ atom, which moves from the $\mathrm{H} 1$ site to the $\mathrm{B} 3$ site (between one $\mathrm{C} \equiv \mathrm{C}$ bond). The $\mathrm{CO}$ obtains $-0.080 \mathrm{e}$ from Pd-graphyne, indicating its role as an electron acceptor. The adsorption energy of $\mathrm{CO}$ on Pd-graphyne reaches $-1.11 \mathrm{eV}$, which is the largest among these four molecules. The adsorption of $\mathrm{C}_{2} \mathrm{H}_{2}$ exhibits only $-0.16 \mathrm{eV}$ adsorption energy, with a very small electron transfer $(-0.015 \mathrm{e})$ compared to other adsorptions. Finally, one sp hybridized $\mathrm{C}$ atom is right above the $\mathrm{Pd}$ atom. The $\mathrm{CH}_{4}$ adsorption has $-0.13 \mathrm{eV}$ adsorption energy and -0.063 e electron transfer. For the adsorption of $\mathrm{C}_{2} \mathrm{H}_{2}$ and $\mathrm{CH}_{4}$, the adsorption distance is much larger compared to the adsorption of $\mathrm{H}_{2}$ and $\mathrm{CO}$, and the position of the Pd atom is unchanged. To sum up, only $\mathrm{CO}$ adsorption causes a significant change in the structure of Pd-graphyne, with much larger adsorption energy.
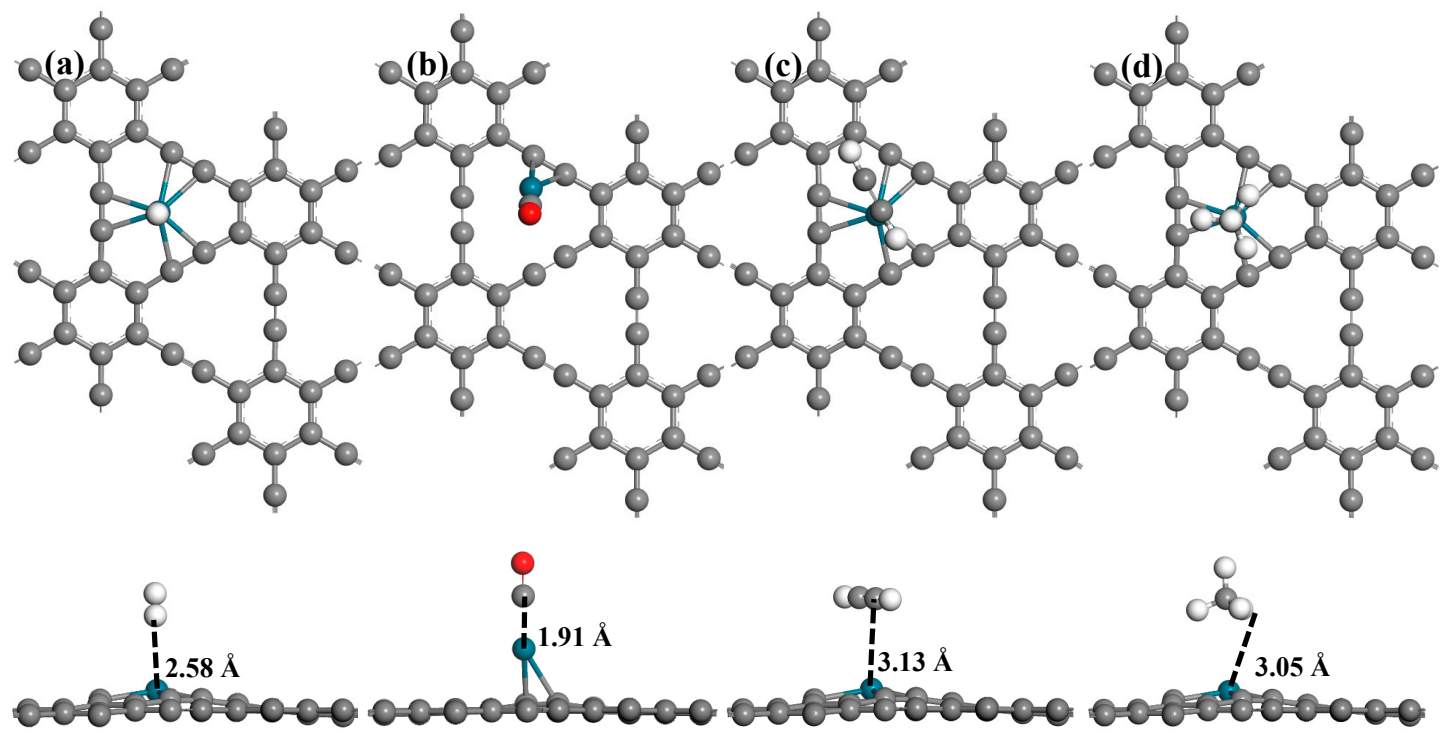

Figure 4. Optimized geometric structures of four kinds of molecule adsorbed on Pd-graphyne: (a) $\mathrm{H}_{2}$ adsorption; (b) $\mathrm{CO}$ adsorption; (c) $\mathrm{C}_{2} \mathrm{H}_{2}$ adsorption; (d) $\mathrm{CH}_{4}$ adsorption.

Table 2. Adsorption energy and electron transfer of $\mathrm{H}_{2}, \mathrm{CO}, \mathrm{C}_{2} \mathrm{H}_{2}$, or $\mathrm{CH}_{4}$ adsorbed on Pd-graphyne.

\begin{tabular}{ccc}
\hline Structure & $\boldsymbol{E}_{\text {ads }}(\mathbf{e V})$ & $\boldsymbol{Q}_{T}(\mathbf{e})$ \\
\hline Pd-graphyne $/ \mathrm{H}_{2}$ & -0.08 & -0.059 \\
Pd-graphyne $/ \mathrm{CO}$ & -1.11 & -0.080 \\
Pd-graphyne $/ \mathrm{C}_{2} \mathrm{H}_{2}$ & -0.16 & -0.015 \\
Pd-graphyne $/ \mathrm{CH}_{4}$ & -0.13 & -0.063 \\
\hline
\end{tabular}

To perform a more advanced analysis of the interactions, the electron density difference (EDD) was calculated; the results are shown in Figure 5. For the adsorption of $\mathrm{H}_{2}$, an obvious electron accumulation occurs near the upper $\mathrm{H}$ atom and between the $\mathrm{H}_{2}$ and $\mathrm{Pd}$ atoms, while the depletion region is between the two $\mathrm{H}$ atoms. However, Pd-graphyne does not show any obvious electron density 
change. The $\mathrm{CO}$ adsorption results in an obvious change of the electron distribution. An apparent electron accumulation occurs between the molecule and the $\mathrm{Pd}$ atom, while the depletion is around $\mathrm{Pd}$ and between $\mathrm{C}$ and $\mathrm{O}$ atoms. The electrons prefer to move between the molecule and the Pd atom, rather than beneath the $\mathrm{Pd}$. The adsorption of $\mathrm{C}_{2} \mathrm{H}_{2}$ causes obvious electron depletion around $\mathrm{Pd}$, and changes the electron distribution of Pd-graphyne to some extent. As for the adsorption of $\mathrm{CH}_{4}$, only a slight depletion region can be found around the Pd atom. Given the different isosurface in Figure 5b, the $\mathrm{CO}$ adsorption yields the largest electron redistribution, and the $\mathrm{C}_{2} \mathrm{H}_{2}$ adsorption also causes a considerable change in the electron density of the Pd-graphyne; however, the other two adsorptions only result in a smaller effect. The relationship of electron transfer and electronic properties after adsorption will be discussed in the following section.

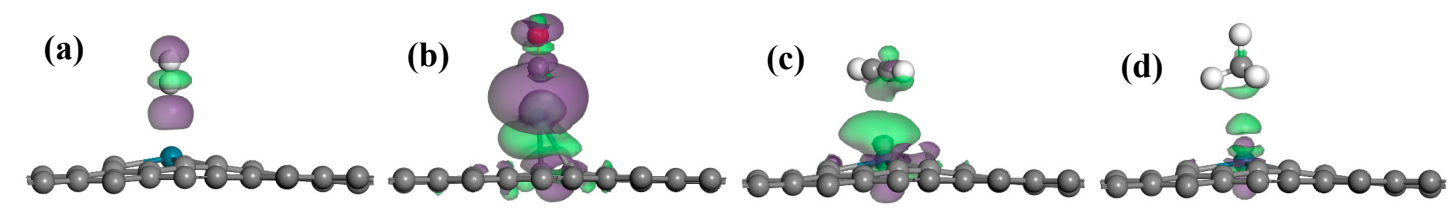

Figure 5. Electron density difference (EDD) of four kinds of molecules adsorbed on Pd-graphyne: (a) $\mathrm{H}_{2}$ adsorption; (b) $\mathrm{CO}$ adsorption; (c) $\mathrm{C}_{2} \mathrm{H}_{2}$ adsorption; (d) $\mathrm{CH}_{4}$ adsorption. The purple region denotes the electron accumulation region, while the green region represents electron depletion (the isosurface of (a), (c), and (d) is $0.005 \mathrm{e}^{-3}$; the isosurface of (b) is $0.02 \mathrm{e}^{-3}$ ).

\subsection{Electronic Properties of Pd-Graphyne and Gas Sensing Evaluation}

To investigate the effect upon the electronic properties of the Pd-graphyne, the band structure and DOS before and after adsorption were compared. The band structures of Pd-graphyne after adsorbing gas molecules are shown in Figure 6. All the band structures still show a direct band gap, but the gap values have some differences. The $\mathrm{H}_{2}$ and $\mathrm{CH}_{4}$ adsorptions do not exhibit any obvious change of band structure. However, the $\mathrm{CO}$ adsorption increases the band gap, while $\mathrm{C}_{2} \mathrm{H}_{2}$ decreases it. Considering the electron distribution in Figure 5, only the adsorptions of $\mathrm{CO}$ and $\mathrm{C}_{2} \mathrm{H}_{2}$ yield obvious changes in electron distribution and change the electronic properties of Pd-graphyne. As a result, the band gap changes only after the adsorption of $\mathrm{CO}$ and $\mathrm{C}_{2} \mathrm{H}_{2}$.
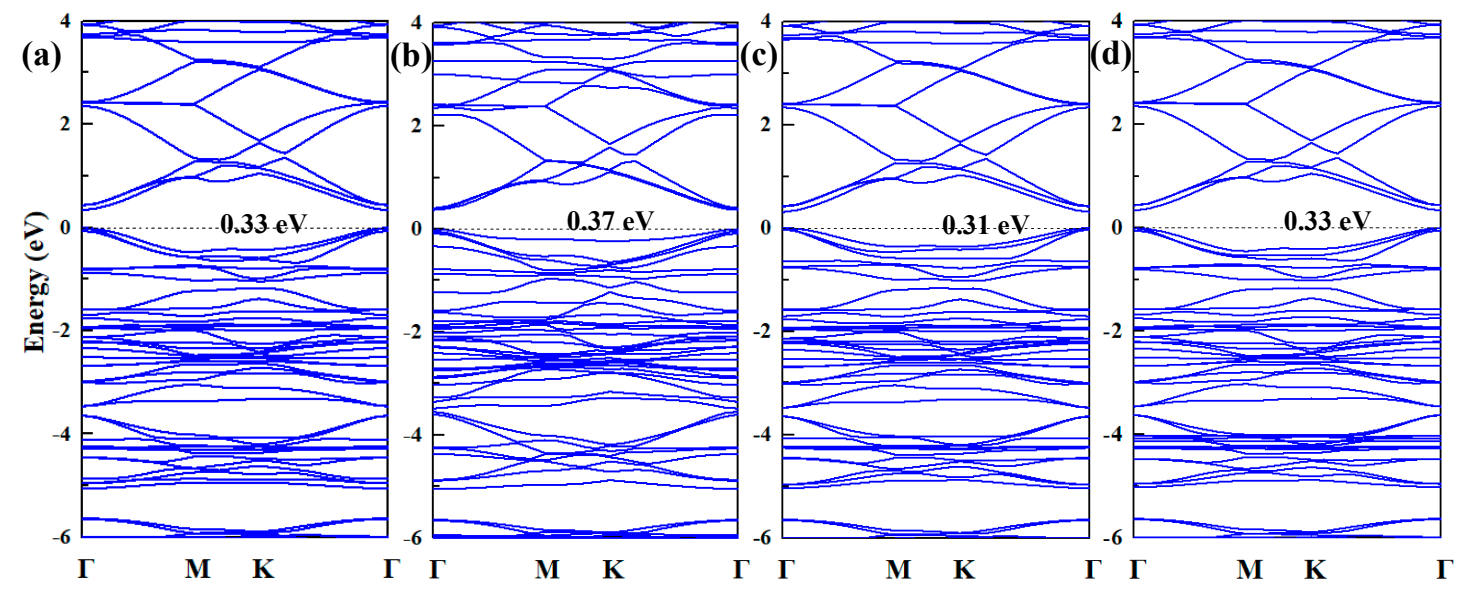

Figure 6. Band structure of (a) Pd-graphyne $/ \mathrm{H}_{2} ;(\mathbf{b}) \mathrm{Pd}$-graphyne/CO; (c) Pd-graphyne $/ \mathrm{C}_{2} \mathrm{H}_{2}$; and (d) Pd-graphyne/ $\mathrm{CH}_{4}$.

To further investigate the electronic properties, the TDOS of Pd-graphyne after adsorption and the PDOS of the adsorbed molecule are shown in Figure 7. For the adsorption of $\mathrm{H}_{2}$ and $\mathrm{CH}_{4}$, the states near the Fermi level do not exhibit obvious changes. However, the adsorbed $\mathrm{CO}$ or $\mathrm{C}_{2} \mathrm{H}_{2}$ molecule introduces several impurity states just below the Fermi level; thus, these states change the electronic properties of the Pd-graphyne near $0 \mathrm{eV}$. Furthermore, the new band gap has some 
differences compared to the Pd-graphyne before adsorption. Because the $\mathrm{CO}$ adsorption has a much shorter adsorption distance, larger adsorption energy, and significant changes in structure and electron distribution, the chemical interactions between the $\mathrm{Pd}$ atom and $\mathrm{CO}$ are explored using the PDOS of the atomic orbitals of the $\mathrm{Pd}$ and $\mathrm{C}$ atoms in $\mathrm{CO}$, as shown in Figure 7e. The states between $-7 \mathrm{eV}$ and $-6 \mathrm{eV}$ consist of $\mathrm{Pd} 5 \mathrm{~s}, \mathrm{Pd} 4 \mathrm{~d}$, and C $2 \mathrm{p}$ orbitals. The states between $-3 \mathrm{eV}$ and $0 \mathrm{eV}$ are mainly $\mathrm{Pd} 4 \mathrm{~d}$ and $5 \mathrm{~s}$ orbitals. As for the antibonding orbitals above $0 \mathrm{eV}$, the states are composed of $\mathrm{Pd} 4 \mathrm{~d}$, $5 p$, and $\mathrm{C} 2 \mathrm{p}$ orbitals. The obvious hybridizations of peaks near $-6 \mathrm{eV}$ and $+3 \mathrm{eV}$ between the $\mathrm{Pd}$ and $C$ atomic orbitals show significant chemical interactions between these two atoms. In summary, the largest adsorption energy $(-1.11 \mathrm{eV})$, largest electron transfer $(-0.080 \mathrm{e})$ of $\mathrm{CO}$ compared to other adsorptions, and the significant state hybridization between the $\mathrm{Pd}$ and $\mathrm{C}$ atoms provide evidence for the strong interactions between $\mathrm{CO}$ and Pd-graphyne.
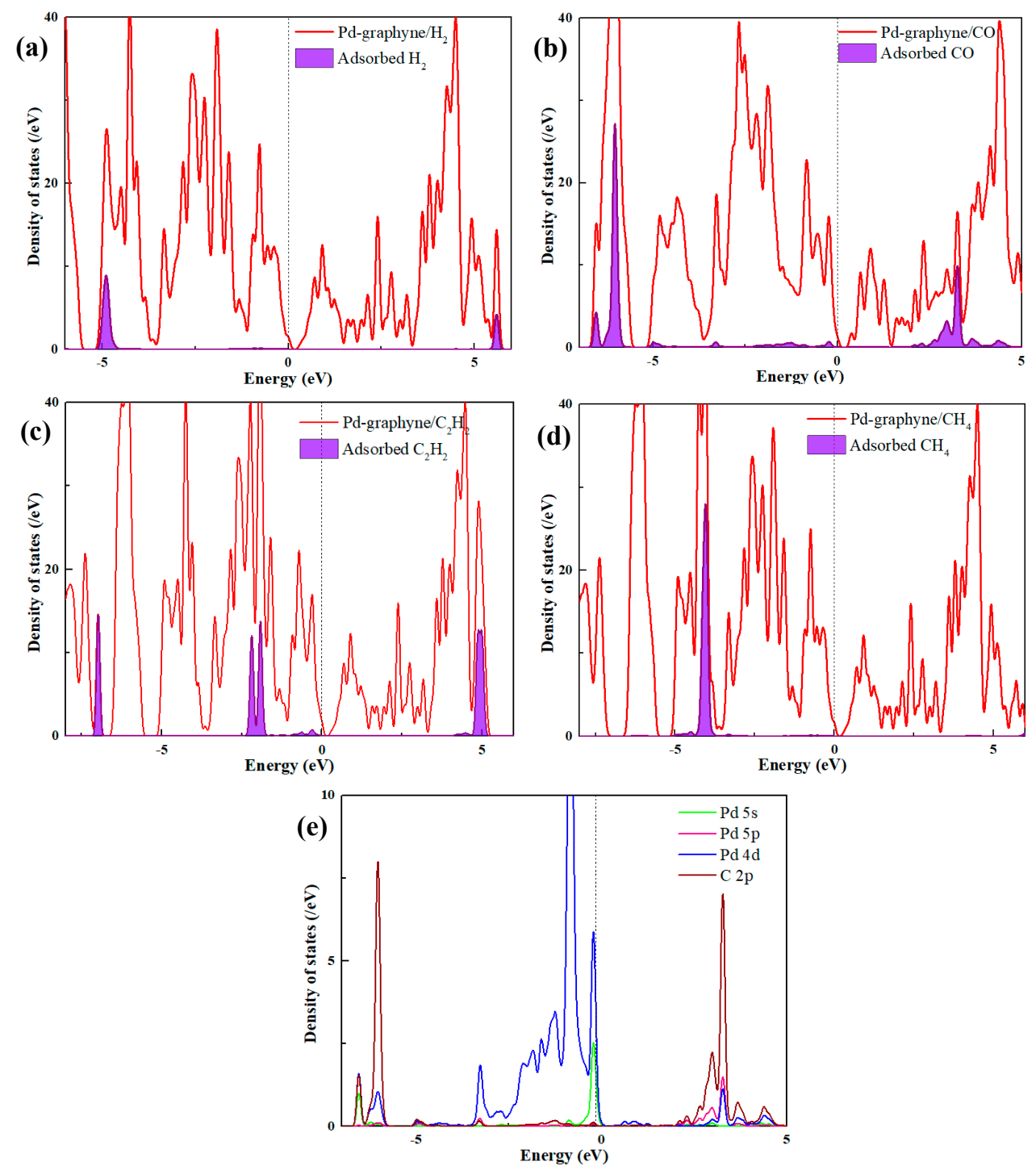

Figure 7. TDOS and PDOS of (a) Pd-graphyne/ $\mathrm{H}_{2}$; (b) Pd-graphyne/CO; (c) Pd-graphyne/ $\mathrm{C}_{2} \mathrm{H}_{2}$; (d) Pd-graphyne $/ \mathrm{CH}_{4}$; and (e) atomic orbitals of $\mathrm{CO}$ adsorption.

Resistance type gas sensors have attracted much attention for their gas sensing properties. Electrical conductivity is strongly affected by the band structure of the sensing materials, and the change of the resistance can be evaluated by the band gap [56]:

$$
\sigma \propto e^{\left(-E_{g} / 2 k_{B} T\right)}
$$


where $\sigma$ represents the evaluated conductance of the gas sensor, $k_{B}$ is the Boltzmann constant, and $T$ is the working temperature of the gas sensor. It can be seen that in a fixed working temperature, a smaller band gap leads to a larger conductance and vice versa. In this study, the band gap of Pd-graphyne is $0.33 \mathrm{eV}$, increasing to $0.37 \mathrm{eV}$ when adsorbing $\mathrm{CO}$, while decreasing to $0.31 \mathrm{eV}$ after $\mathrm{C}_{2} \mathrm{H}_{2}$ adsorption. As a result, the conductance rises when detecting $\mathrm{C}_{2} \mathrm{H}_{2}$ and falls when adsorbing $\mathrm{CO}$. However, another point should be also considered: the recovery time of the sensor is an important aspect relative to its the sensing properties. A very short recovery time can promote the desorption process, but rapid desorption may lead to a higher limit of detection. So, the recovery time should be kept within an acceptable range. The recovery time can be evaluated as follows [57]:

$$
\tau=A^{-1} e^{\left(-E_{b a r} / k_{B} T\right)}
$$

where $A$ denotes the apparent frequency factor, $k_{B}$ is the Boltzmann's constant, and $T$ is the working temperature, respectively. $E_{b a r}$ is the energy barrier of the molecule desorption from the surface. For the adsorption of $\mathrm{H}_{2}, \mathrm{CO}$, and $\mathrm{C}_{2} \mathrm{H}_{2}$, as shown in Figure 4, during the adsorption process, the structure of Pd-graphyne shows nearly no change, and no chemical bonds are broken. As a result, the adsorption does not undergo any endothermic process, and has no energy barrier. Moreover, these three adsorptions mainly show Van der Waals interactions, and no obvious bond formation nor bond breakages have been observed. So, the desorption process of these three gas molecules will not experience a transition state, and the energy barrier of the desorption can be seen as the absolute value of the adsorption energy. The transition state of the adsorption process for $\mathrm{CO}$ is shown in Figure 8. It can be seen that the value of the energy barrier of the desorption process is only 1.11-0.04 $=1.07 \mathrm{eV}$. This value is smaller than the adsorption energy of $\mathrm{CO}(1.11 \mathrm{eV})$. As a result, the total energy barrier of desorption is still $1.11 \mathrm{eV}$, which is the same as that of the adsorption energy. So, for these four adsorptions, the absolute values of $E_{b a r}$ and $E_{a d s}$ are the same. The value of $A$ can be evaluated as $10^{12} \mathrm{~s}^{-1}$, which is consistent with results published in other studies [58]. According to the above precondition, the desorption times of $\mathrm{H}_{2}, \mathrm{C}_{2} \mathrm{H}_{2}$, and $\mathrm{CH}_{4}$ are $2.25 \times 10^{-11} \mathrm{~s}, 5.08 \times 10^{-10} \mathrm{~s}$, and $1.58 \times 10^{-10} \mathrm{~s}$, which are much smaller than that of $\mathrm{CO}$, i.e., $5.92 \times 10^{-6} \mathrm{~s}$ at $298 \mathrm{~K}$. At room temperature, $\mathrm{CO}$ is hard to desorb from the surface, but much faster desorption of $\mathrm{C}_{2} \mathrm{H}_{2}$ may result in a much higher detection limit. However, if the working temperature reaches $498 \mathrm{~K}$, the desorption time of CO decreases to about $0.171 \mathrm{~s}$; this shorter time is suitable for $\mathrm{CO}$ sensing. As a result, the Pd-graphyne-based gas sensor may have very good selectivity for $\mathrm{CO}$ at higher temperatures.

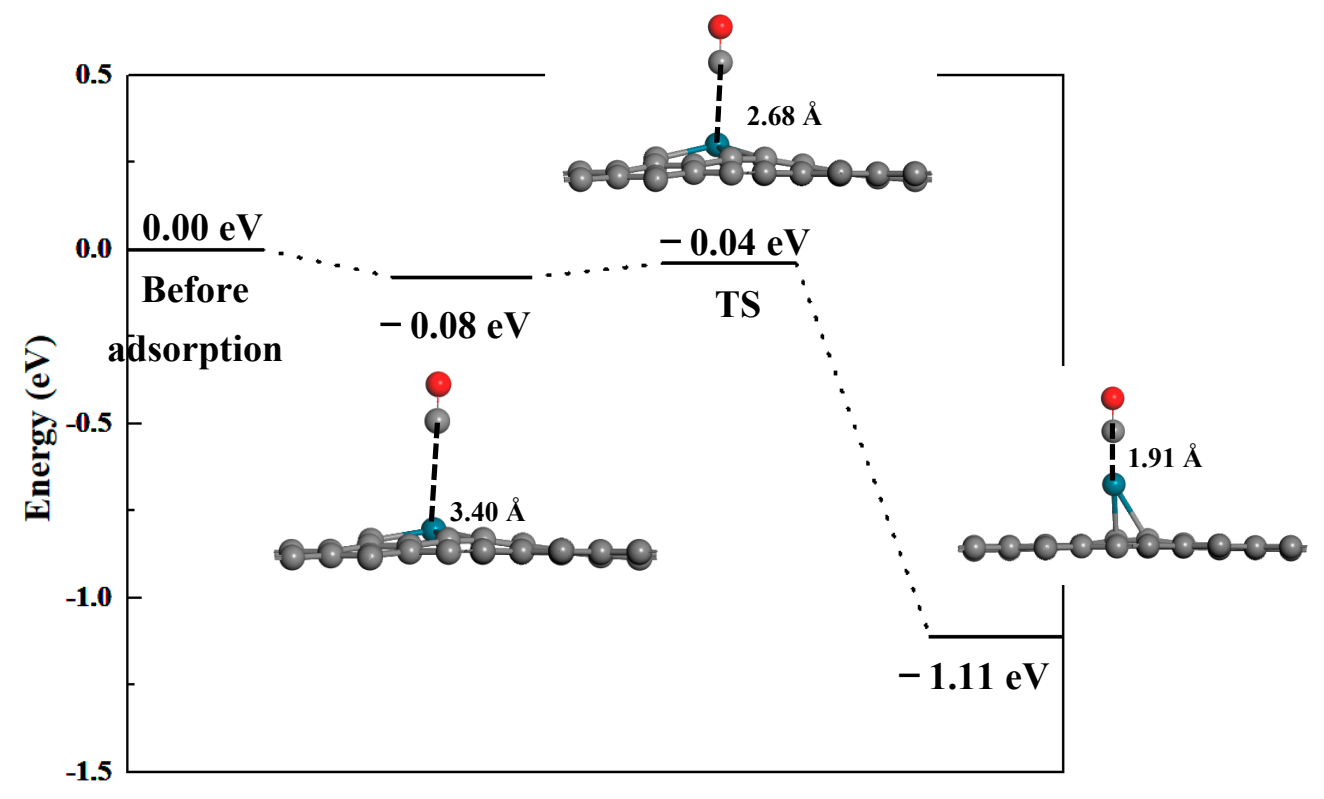

Figure 8. Transition state of CO adsorption on Pd-graphyne. 


\section{Conclusions}

This study discussed the structure and electronic properties of Pd-graphyne, as well as its adsorption properties for four common dissolved gases in transformer oil $\left(\mathrm{H}_{2}, \mathrm{CO}, \mathrm{C}_{2} \mathrm{H}_{2}\right.$, and $\left.\mathrm{CH}_{4}\right)$. $\mathrm{Pd}$ atoms prefer to be adsorbed on the $\mathrm{H} 1$ site with the largest binding energy $(-2.45 \mathrm{eV})$ and electron transfer $(+0.363 \mathrm{e})$. The introduction of a Pd atom decreases the band gap and brings in impurity states just below $0 \mathrm{eV}$. Among the four types of gases, $\mathrm{CO}$ adsorption yields the largest adsorption energy and electron transfer. Moreover, the Pd atom moves from the H1 site to B3 site, resulting in obvious changes in the geometric structure and electronic properties of Pd-graphyne. The band gap becomes larger after $\mathrm{CO}$ adsorption, but smaller after $\mathrm{C}_{2} \mathrm{H}_{2}$ adsorption. The strong chemical interactions between Pd-graphyne and adsorbed $\mathrm{CO}$ are mainly attributed to the hybridization of the atomic orbitals of the $\mathrm{Pd}$ and $\mathrm{C}$ in $\mathrm{CO}$. The recovery properties of the Pd-graphyne-based gas sensor show that the recovery time is about $0.171 \mathrm{~s}$ for $\mathrm{CO}$ desorption at $498 \mathrm{~K}$. This acceptable result indicates that this approach may be applied in the realization of a high selectivity gas sensor for $\mathrm{CO}$ detection.

Author Contributions: X.Z. and D.C. proposed the project and organized the manuscript. R.F. and G.Z. contributed to the theoretical simulation and analyzed the simulation results. All authors read and approved the final manuscript.

Funding: This research was funded by the National Natural Science Foundation of China under Grant 51777144.

Conflicts of Interest: The authors declare no conflict of interest.

\section{References}

1. Novoselov, K.S.; Geim, A.K.; Morozov, S.V.; Jiang, D.; Zhang, Y.; Dubonos, S.V.; Grigorieva, I.V.; Firsov, A.A. Electric field effect in atomically thin carbon films. Science 2004, 306, 666. [CrossRef]

2. Sun, P.; Wang, K.; Zhu, H. Recent developments in graphene-based membranes: Structure, mass-transport mechanism and potential applications. Adv. Mater. 2016, 28, 2287-2310. [CrossRef] [PubMed]

3. Huang, X.; Yin, Z.; Wu, S.; Qi, X.; He, Q.; Zhang, Q.; Yan, Q.; Boey, F.; Zhang, H. Graphene-based materials: Synthesis, characterization, properties, and applications. Small 2011, 7, 1876-1902. [CrossRef] [PubMed]

4. Singh, V.; Joung, D.; Zhai, L.; Das, S.; Khondaker, S.I.; Seal, S. Graphene based materials: Past, present and future. Prog. Mater. Sci. 2011, 56, 1178-1271. [CrossRef]

5. $\mathrm{Hu}, \mathrm{Z} . ; \mathrm{Wu}, \mathrm{Z} . ; \mathrm{Han}, \mathrm{C} . ; \mathrm{He}$ J.; Ni, Z.; Chen, W. Two-dimensional transition metal dichalcogenides: Interface and defect engineering. Chem. Soc. Rev. 2018, 47,3100-3128. [CrossRef]

6. Tan, C.; Zhang, H. Two-dimensional transition metal dichalcogenide nanosheet-based composites. Chem. Soc. Rev. 2015, 44, 2713-2731. [CrossRef]

7. Rajkamal, A.; Thapa, R. Carbon allotropes as anode material for lithium-ion batteries. Adv. Mater. Technol. 2019. [CrossRef]

8. Naguib, M.; Mochalin, V.N.; Barsoum, M.W.; Gogotsi, Y. 25th anniversary article: Mxenes: A new family of two-dimensional materials. Adv. Mater. 2014, 26, 992-1005. [CrossRef]

9. Zhao, M.; Huang, Y.; Peng, Y.; Huang, Z.; Ma, Q.; Zhang, H. Two-dimensional metal-organic framework nanosheets: Synthesis and applications. Chem. Soc. Rev. 2018, 47, 6267-6295. [CrossRef]

10. Li, Y.; Xu, L.; Liu, H.; Li, Y. Graphdiyne and graphyne: From theoretical predictions to practical construction. Chem. Soc. Rev. 2014, 43, 2572-2586. [CrossRef]

11. Huang, C.; Li, Y.; Wang, N.; Xue, Y.; Zuo, Z.; Liu, H.; Li, Y. Progress in research into 2d graphdiyne-based materials. Chem. Rev. 2018, 118, 7744-7803. [CrossRef] [PubMed]

12. Sakamoto, R.; Fukui, N.; Maeda, H.; Matsuoka, R.; Toyoda, R.; Nishihara, H. The accelerating world of graphdiynes. Adv. Mater. 2019, 1804211. [CrossRef] [PubMed]

13. Ruiz-Puigdollers, A.; Gamallo, P. DFT study of the role of N- and B-doping on structural, elastic and electronic properties of $\alpha-, \beta$ - and $\gamma$-graphyne. Carbon 2017, 114, 301-310. [CrossRef]

14. Kim, B.G.; Choi, H.J. Graphyne: Hexagonal network of carbon with versatile Dirac cones. Phys. Rev. B 2012, 86, 115435. [CrossRef]

15. Li, G.; Li, Y.; Liu, H.; Guo, Y.; Li, Y.; Zhu, D. Architecture of graphdiyne nanoscale films. Chem. Commun. 2010, 46, 3256-3258. [CrossRef] [PubMed] 
16. Gao, X.; Zhou, Y.; Tan, Y.; Liu, S.; Cheng, Z.; Shen, Z. Graphyne doped with transition-metal single atoms as effective bifunctional electrocatalysts for water splitting. Appl. Surf. Sci. 2019, 492, 8-15. [CrossRef]

17. He, T.; Matta, S.K.; Du, A. Single tungsten atom supported on N-doped graphyne as a high-performance electrocatalyst for nitrogen fixation under ambient conditions. Phys. Chem. Chem. Phys. 2019, 21, 1546-1551. [CrossRef]

18. Kim, S.; Ruiz Puigdollers, A.; Gamallo, P.; Viñes, F.; Lee, J.Y. Functionalization of $\gamma$-graphyne by transition metal adatoms. Carbon 2017, 120, 63-70. [CrossRef]

19. He, J.; Zhou, P.; Jiao, N.; Ma, S.Y.; Zhang, K.W.; Wang, R.Z.; Sun, L.Z. Magnetic exchange coupling and anisotropy of $3 \mathrm{~d}$ transition metal nanowires on graphyne. Sci. Rep. 2014, 4, 4014. [CrossRef]

20. Kang, B.; Shi, H.; Wang, F.-F.; Lee, J.Y. Importance of doping site of B, N, and O in tuning electronic structure of graphynes. Carbon 2016, 105, 156-162. [CrossRef]

21. Kang, B.; Ai, H.; Lee, J.Y. Single-atom vacancy induced changes in electronic and magnetic properties of graphyne. Carbon 2017, 116, 113-119. [CrossRef]

22. Chen, Z.W.; Wen, Z.; Jiang, Q. Rational design of Ag38 cluster supported by graphdiyne for catalytic co oxidation. J. Phys. Chem. C 2017, 121, 3463-3468. [CrossRef]

23. Chen, D.; Zhang, X.; Tang, J.; Cui, H.; Li, Y.; Zhang, G.; Yang, J. Density functional theory study of small Ag cluster adsorbed on graphyne. Appl. Surf. Sci. 2019, 465, 93-102. [CrossRef]

24. Seif, A.; López, M.J.; Granja-DelRío, A.; Azizi, K.; Alonso, J.A. Adsorption and growth of palladium clusters on graphdiyne. Phys. Chem. Chem. Phys. 2017, 19, 19094-19102. [CrossRef] [PubMed]

25. Meng, Z.; Zhang, X.; Zhang, Y.; Gao, H.; Wang, Y.; Shi, Q.; Rao, D.; Liu, Y.; Deng, K.; Lu, R. Graphdiyne as a high-efficiency membrane for separating oxygen from harmful gases: A first-principles study. ACS Appl. Mater. Interfaces 2016, 8, 28166-28170. [CrossRef]

26. Lu, Z.; Lv, P.; Ma, D.; Yang, X.; Li, S.; Yang, Z. Detection of gas molecules on single Mn adatom adsorbed graphyne: A DFT-D study. J. Phys. D-Appl. Phys. 2018, 51, 065109. [CrossRef]

27. Omidvar, A.; Mohajeri, A. Decorated graphyne and its boron nitride analogue as versatile nanomaterials for CO detection. Mol. Phys. 2015, 113, 3900-3908. [CrossRef]

28. Peyghan, A.A.; Rastegar, S.F.; Hadipour, N.L. DFT study of $\mathrm{NH}_{3}$ adsorption on pristine, Ni- and Si-doped graphynes. Phys. Lett. A 2014, 378, 2184-2190. [CrossRef]

29. Guo, Y.; Chen, Z.; Wu, W.; Liu, Y.; Zhou, Z. Adsorption of NOx $(x=1,2)$ gas molecule on pristine and B atom embedded $\gamma$-graphyne based on first-principles study. Appl. Surf. Sci. 2018, 455, 484-491. [CrossRef]

30. Nagarajan, V.; Srimathi, U.; Chandiramouli, R. First-principles insights on detection of dimethyl amine and trimethyl amine vapors using graphdiyne nanosheets. Comput. Theor. Chem. 2018, 1123, 119-127. [CrossRef]

31. Ma, D.W.; Li, T.; Wang, Q.; Yang, G.; He, C.; Ma, B.; Lu, Z. Graphyne as a promising substrate for the noble-metal single-atom catalysts. Carbon 2015, 95, 756-765. [CrossRef]

32. Chen, D.; Zhang, X.; Cui, H.; Tang, J.; Pi, S.; Cui, Z.; Li, Y.; Zhang, Y. High selectivity n-type InSe monolayer toward decomposition products of sulfur hexafluoride: A density functional theory study. Appl. Surf. Sci. 2019, 479, 852-862. [CrossRef]

33. Chen, D.; Zhang, X.; Xiong, H.; Li, Y.; Tang, J.; Xiao, S.; Zhang, D. A first-principles study of the $\mathrm{SF}_{6}$ decomposed products adsorbed over defective $\mathrm{WS}_{2}$ monolayer as promising gas sensing device. IEEE Trans. Device Mater. Reliab. 2019, 19, 473-483. [CrossRef]

34. Chen, D.; Zhang, X.; Tang, J.; Pi, S.; Li, Y.; Cui, Z. High Selective $\mathrm{SO}_{2}$ Gas Sensor Based on Monolayer $\beta$-AsSb to Detect $\mathrm{SF}_{6}$ Decompositions. IEEE Sens. J. 2018, 19, 1215-1223. [CrossRef]

35. Chen, D.; Tang, J.; Zhang, X.; Li, Y.; Liu, H. Detecting decompositions of sulfur hexafluoride using $\mathrm{MoS}_{2}$ monolayer as gas sensor. IEEE Sens. J. 2018, 19, 39-46. [CrossRef]

36. Chen, D.; Zhang, X.; Tang, J.; Cui, Z.; Cui, H. Pristine and Cu decorated hexagonal Inn monolayer, a promising candidate to detect and scavenge $\mathrm{SF}_{6}$ decompositions based on first-principle study. J. Hazard. Mater. 2019, 363, 346-357. [CrossRef] [PubMed]

37. Chen, D.; Zhang, X.; Tang, J.; Cui, Z.; Cui, H.; Pi, S. Theoretical study of monolayer PtSe 2 as outstanding gas sensor to detect $\mathrm{SF}_{6}$ decompositions. IEEE Electron. Device Lett. 2018, 39, 1405-1408. [CrossRef]

38. Zhang, D.; Wu, J.; Li, P.; Cao, Y. Room-temperature $\mathrm{SO}_{2}$ gas-sensing properties based on a metal-doped $\mathrm{MoS}_{2}$ nanoflower: An experimental and density functional theory investigation. J. Mater. Chem. A 2017, 5, 20666-20677. [CrossRef] 
39. Chu, J.; Wang, X.; Wang, D.; Yang, A.; Lv, P.; Wu, Y.; Rong, M.; Gao, L. Highly selective detection of sulfur hexafluoride decomposition components $\mathrm{H}_{2} \mathrm{~S}$ and $\mathrm{SOF}_{2}$ employing sensors based on tin oxide modified reduced graphene oxide. Carbon 2018, 135, 95-103. [CrossRef]

40. Cui, H.; Zhang, X.; Li, Y.; Chen, D.; Zhang, Y. First-principles insight into Ni-doped Inn monolayer as a noxious gases scavenger. Appl. Surf. Sci. 2019, 494, 859-866. [CrossRef]

41. Cui, H.; Liu, T.; Zhang, Y.; Zhang, X. Ru-InN Monolayer as a Gas Scavenger to Guard the Operation Status of $\mathrm{SF}_{6}$ Insulation Devices: A First-Principles Theory. IEEE Sens. J. 2019, 19, 5249-5255. [CrossRef]

42. Zhang, Q.; Zhou, Q.; Lu, Z.; Wei, Z.; Xu, L.; Gui, Y. Recent advances of $\mathrm{SnO}_{2}$-based sensors for detecting fault characteristic gases extracted from power transformer oil. Front. Chem. 2018, 6, 364. [CrossRef] [PubMed]

43. Fan, J.; Wang, F.; Sun, Q.; Ye, H.; Jiang, Q. Application of polycrystalline $\mathrm{SnO}_{2}$ sensor chromatographic system to detect dissolved gases in transformer oil. Sens. Actuator B-Chem. 2018, 267, 636-646. [CrossRef]

44. Uddin, A.S.M.I.; Yaqoob, U.; Chung, G.-S. Dissolved hydrogen gas analysis in transformer oil using Pd catalyst decorated on $\mathrm{ZnO}$ nanorod array. Sens. Actuator B-Chem. 2016, 226, 90-95. [CrossRef]

45. Chen, W.; Zhou, Q.; Gao, T.; Su, X.; Wan, F. Pd-doped $\mathrm{SnO}_{2}$-based sensor detecting characteristic fault hydrocarbon gases in transformer oil. J. Nanomater. 2013, 2013, 9. [CrossRef]

46. Chen, Z.; Zhang, X.; Xiong, H.; Chen, D.; Cheng, H.; Tang, J.; Tian, Y.; Xiao, S. Dissolved Gas Analysis in Transformer Oil Using Pt-Doped WSe 2 Monolayer Based on First Principles Method. IEEE Access 2019, 7, 72012-72019. [CrossRef]

47. Cui, H.; Zhang, X.; Zhang, G.; Tang, J. Pd-doped $\mathrm{MoS}_{2}$ monolayer: A promising candidate for DGA in transformer oil based on DFT method. Appl. Surf. Sci. 2019, 470, 1035-1042. [CrossRef]

48. Zhang, Y.; Sun, X.; Tan, S.; Liu, T.; Cui, H. Adsorption characteristic of Rh-doped MoSe 2 monolayer towards $\mathrm{H}_{2}$ and $\mathrm{C}_{2} \mathrm{H}_{2}$ for DGA in transformer oil based on DFT method. Appl. Surf. Sci. 2019, 487, 930-937. [CrossRef]

49. Delley, B. Dmol3 DFT studies: From molecules and molecular environments to surfaces and solids. Comput. Mater. Sci. 2000, 17, 122-126. [CrossRef]

50. Perdew, J.P.; Chevary, J.A.; Vosko, S.H.; Jackson, K.A.; Pederson, M.R.; Singh, D.J.; Fiolhais, C. Atoms, molecules, solids, and surfaces: Applications of the generalized gradient approximation for exchange and correlation. Phys. Rev. B 1992, 46, 6671-6687. [CrossRef]

51. Perdew, J.P.; Burke, K.; Ernzerhof, M. Generalized gradient approximation made simple. Phys. Rev. Lett. 1996, 77, 3865-3868. [CrossRef] [PubMed]

52. Grimme, S. Semiempirical GGA- type density functional constructed with a long- range dispersion correction. J. Comput. Chem. 2006, 27, 1787-1799. [CrossRef] [PubMed]

53. Monkhorst, H.J.; Pack, J.D. Special points for Brillouin-zone integrations. Phys. Rev. B 1976, 13, 5188. [CrossRef]

54. Hirshfeld, F.L. Bonded-atom fragments for describing molecular charge densities. Theor. Chem. Acta 1977, 44, 129-138. [CrossRef]

55. Kang, B.; Lee, J.Y. Graphynes as promising cathode material of fuel cell: Improvement of oxygen reduction efficiency. J. Phys. Chem. C 2014, 118, 12035-12040. [CrossRef]

56. Li, S.S. Semiconductor Physical Electronics; Springer Science \& Business Media: New York, NY, USA, 2012.

57. Zhang, Y.H.; Chen, Y.B.; Zhou, K.G.; Liu, C.H.; Zeng, J.; Zhang, H.L.; Peng, Y. Improving gas sensing properties of graphene by introducing dopants and defects: A first-principles study. Nanotechnology 2009, 20, 185504. [CrossRef]

58. Patel, K.; Roondhe, B.; Dabhi, S.D.; Jha, P.K. A new flatland buddy as toxic gas scavenger: A first principles study. J. Hazard. Mater. 2018, 351, 337-345. [CrossRef]

(C) 2019 by the authors. Licensee MDPI, Basel, Switzerland. This article is an open access article distributed under the terms and conditions of the Creative Commons Attribution (CC BY) license (http://creativecommons.org/licenses/by/4.0/). 